\title{
Mortality and stroke after amaurosis fugax
}

\author{
CJM POOLE, RW ROSS RUSSELL
}

From the Departments of Neurology and Medical Ophthalmology, St Thomas's Hospital, London, UK

SUMMARY One hundred and ten patients who had presented with amaurosis fugax and were treated medically were studied retrospectively. Follow up from the time of presentation was six to nineteen years with a median of eight years. The mortality and frequency of strokes in this group was compared with populations matched for age and sex. Life expectancy in patients with amaurosis fugax was reduced. Ischaemic heart disease was the most frequent cause of death and occurred at a greater rate than in the general population $(p<0.01)$. The indicence of stroke was higher than in the Oxfordshire Community Stroke Project 1981-1983 ( $p<0.01)$. Comparing our results to those published for cerebral transient ischaemic attacks, patients with amaurosis fugax have a similar mortality rate but probably have a lower incidence of stroke. Patients with amaurosis fugax who have an occluded or narrowed proximal internal carotid artery have a greater risk of subsequent stroke than those with a normal carotid artery, or an arteriogram $(\mathrm{p}<$ $0 \cdot 01$ ).

Fisher ${ }^{1}$ first drew attention to the association between transient uniocular visual loss and a contralateral hemiplegia in patients with stenosis or occlusion of the internal carotid artery. Whether amaurosis fugax has the same aetiology and natural history as transient cerebral ischaemia is unknown. The best available evidence suggests that the risk of stroke following a cerebral transient ischaemic attack is between 5 and $10 \%$ per annum with maximum risk during the first year immediately after the attack. ${ }^{2}$ Three studies on amaurosis fugax gave widely varying stroke rates..$^{3-5}$ Factors such as age, length of follow up, expected morbidity or mortality for a matched population were not always taken into account. Carotid endarterectomy is frequently performed in patients with amaurosis fugax who have carotid stenosis and both the operative morbidity and the selection of these patients varies between centres.

We report our experience in 110 medically treated patients, comparing their propensity for death and fatal ischaemic heart disease with a calculated expected rate for the general population matched for age and sex. The risk of first stroke (fatal and non fatal) in these patients is compared with the incidence of first stroke from the Oxfordshire Community Stroke Project 1981-1983.

Address for reprint requests: Dr CJM Poole, Department of Neurology, St Thomas's Hospital, London SE1 7EH, UK.

Received 16 November 1984. Accepted 12 January 1985.

\section{Patients}

All 110 patients had been seen either at Moorfields Eye Hospital, Royal Eye Hospital, or St Thomas's Hospital London between 1965 and 1978. They had all received medical treatment which in some cases involved general advice such as stopping smoking and losing weight. In others anti-hypertensives, clofibrate, warfarinco dipyridamole and aspirin were prescribed.

Carotid endarterectomy was not used at St Thomas's Hospital for the treatment of amaurosis fugax until 1969. The sixteen patients who underwent carotid artery surgery for carotid artery stenosis in association with amaurosis fugax between 1969 and 1978 were excluded. Six patients in whom cholesterol emboli were visible in the retinal arteries were removed from the study as they may constitute a different aetiological group.

Amaurosis fugax was defined as partial or complete uniocular visual loss of sudden onset lasting less than one hour. Patients with overt ocular pathology were excluded although five with raised intraocular tension were included.

The patients' general practitioners were contacted by telephone sometimes with the help of the Family Practitioner Committee or Central Registration. If the patient had deceased, a copy of the death certificate was obtained from the Office of Population, Censuses and Surveys. Surviving patients were contacted by telephone or letter.

The patients' notes, general practitioner or the patient themselves were used to derive the following information: age at onset of amaurosis fugax, previous stroke, ischaemic heart disease, hypertension, diabetes and smoking habits. Subsequent death, stroke, ischaemic heart disease or visual loss were recorded. The results of special investigations such as angiography were also noted. A stroke was defined as an episode of focal neurological deficit of sudden onset 
lasting more than 24 hours. Death from ischaemic heart disease included myocardial infarction, coronary thrombosis and cardiac failure due to coronary artery disease.

\section{Statistical methods}

An actuarial life table technique was used for analysis with the starting point when first seen in hospital. Survival curves for the first six years were calculated to make allowance for those lost to follow up. Those who died from non-cardiac or non-stroke causes were regarded as lost to follow up in the year that they died. The expected yearly death rate was derived by using an average death rate for different age groups weighted according to the age distribution of the amaurosis fugax sample (direct standardisation). The average death rates were taken from the 1975 mortality figures for England and Wales as published by the Office of Population, Censuses and Surveys. For fatal ischaemic heart disease ICD codes 410-414 were used. From the expected yearly death rate an expected survival over six years was calculated. The observed and expected number of deaths over six years was then compared using Poisson distribution probabilities.

The incidence of stroke in patients with normal and abnormal angiograms was compared using a chi squared test.

\section{Results}

One hundred and ten patients were identified from hospital records. Thirty-one died and six were lost to follow up. Eighty-two were followed for a minimum of 6 years and a maximum of 19 years. The median and mean length of follow up including death and lost to follow up was 8 years. The male to female ratio was 2.2 to 1.0 . The mean age of the males at presentation was $59(18-79)$ years and the females $61(22-80)$ years. The distribution according to age and sex is shown in table 1 . Risk factors when first seen are shown in table 2 .

Four patients had mixed mitral valve disease and one had mitral valve prolapse. A few others had systolic murmurs and arrhythmias of uncertain significance. One patient had relative polycythaemia. The absence of any patient with an arteritis may be a reflection of diagnostic classification.

Forty-seven ( $43 \%$ ) patients still alive had had no further amaurosis fugax after their presenting episode or episodes.

\section{Mortality}

The mortality in our group of patients with amaurosis fugax steadily increased and at six years was $21 \%$ for males and females combined (fig 1). This compares with an expected mortality of $15 \%$ after 6 years $(p \simeq 0.06)$ for an age matched population in England and Wales. This is due to an increased mortality in men, the observed mortality
Table 1 Distribution of amaurosis fugax by age and sex

\begin{tabular}{lccc}
\hline $\begin{array}{l}\text { Age } \\
(y r)\end{array}$ & $\begin{array}{l}\text { Male } \\
(N=76)\end{array}$ & $\begin{array}{l}\text { Female } \\
(N=34)\end{array}$ & $\begin{array}{l}\text { Total } \\
(N=110)\end{array}$ \\
\hline $15-24$ & 3 & 2 & 5 \\
$25-34$ & 2 & 0 & 2 \\
$35-44$ & 6 & 1 & 7 \\
$45-54$ & 9 & 4 & 13 \\
$55-64$ & 29 & 11 & 40 \\
$65-74$ & 21 & 10 & 31 \\
$>75$ & 6 & 6 & 12 \\
\hline
\end{tabular}

Table 2 Prognostic variables at the time of presentation

\begin{tabular}{ll}
\hline Mean age & 60 years \\
Smoking (cigarettes or pipe) & $58(53 \%)$ \\
Hypertension $(>110 \mathrm{~mm} \mathrm{Hg}$ diastolic or on & \\
treatment) & $2523 \%)$ \\
Ischaemic heart disease & $22(20 \%)$ \\
Intermittent claudication & $16(15 \%)$ \\
Previous stroke & $9(8 \%)$ \\
Diabetes/impaired glucose tolerance & $6(5 \cdot 5 \%)$ \\
\hline
\end{tabular}

after six years for men being $26 \%$ with an expected mortality of $17 \%(\mathrm{p} \approx 0.08)$. The observed mortality for women was $12 \%$ which was very similar to the expected rate of $14 \%$. Myocardial infarction or cardiac failure were the commonest causes of death (table 3), 14 male (18\%) and 3 female (9\%). The observed mortality from this cause in males and females combined at six years was $15 \%$ with a corresponding expected mortality of $4 \%$ (fig 2 ). This is a significant increase in death from cardiac disease $(p<0.01)$.

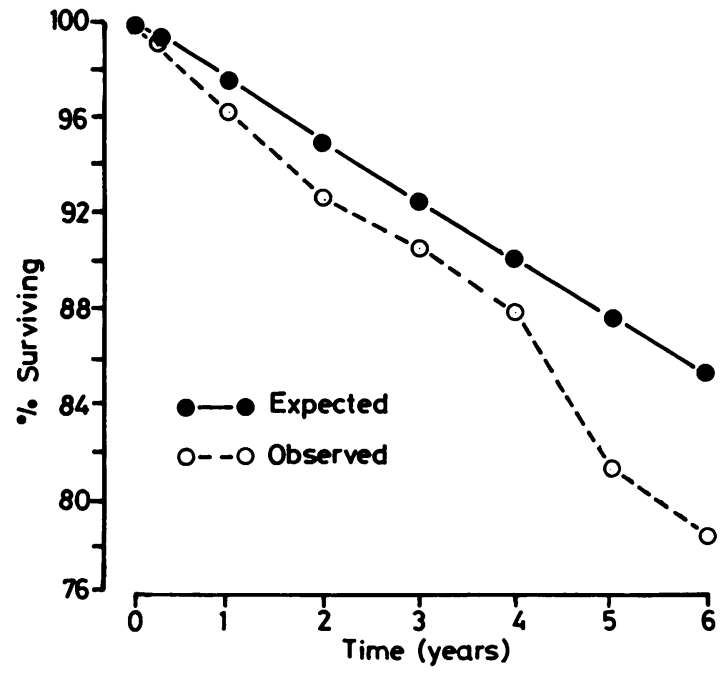

Fig 1 Survival curve for males and females combined after one or more attacks of amaurosis fugax compared with the expected survival for the equivalent age and sex in England and Wales, 1975. 
Table 3 Cause of death following amaurosis fugax

\begin{tabular}{lcc}
\hline Cause & No & \% of total group \\
\hline Cardiac disease & 17 & $15 \cdot 5$ \\
Stroke & 5 & $4 \cdot 5$ \\
Cancer & 5 & $4 \cdot 5$ \\
Respiratory disease & 3 & $2 \cdot 5$ \\
Other & 1 & 1 \\
Total & 31 & 28 \\
\hline
\end{tabular}

The number of strokes (fatal and non fatal) in our sample steadily increased over the first six years of follow up (fig 3). At six years $13 \%$ of the group had suffered a stroke compared with an expected number of $3 \%$ for Oxfordshire, 1981-1983. This is a significant increase in strokes $(p<0.01)$. The youngest patient to have a stroke after amaurosis fugax was aged 57 years at the time of presentation. Patients under the age of 57 constituted $26 \%$ of the group.

Other causes of morbidity after amaurosis fugax included $5(4.5 \%)$ cerebral transient ischaemic attacks, $9(8 \%)$ myocardial infarction or failure and $7(6 \%)$ who lost vision permanently from a retinal artery occlusion or retinal vein thrombosis. In addition two patients developed leukaemia and one Waldenstrom's macroglobulinaemia.

Sixty-four $(58 \%)$ patients underwent angiography. The results and the number suffering a subsequent stroke (fatal and non fatal) are shown in table 4 . In two cases stroke followed immediately on angiography.

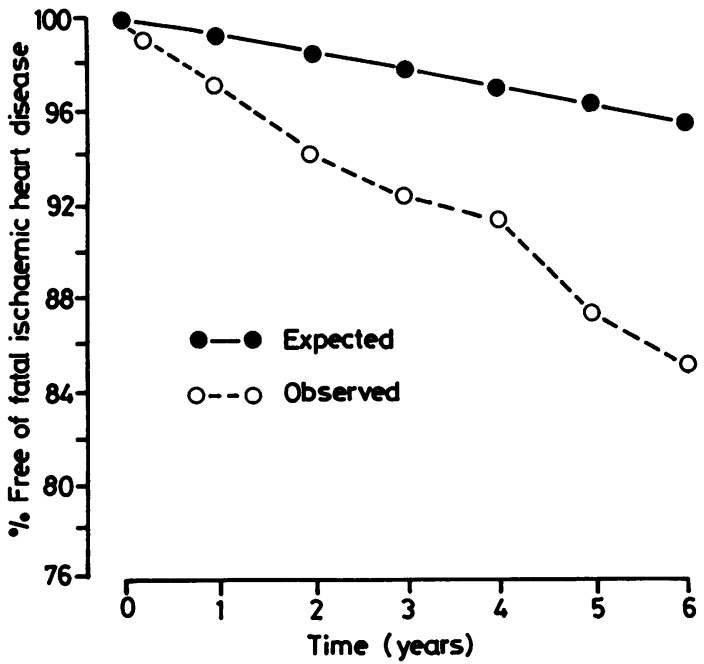

Fig 2 Survival free of fatal ischaemic heart disease for males and females combined after one or more attacks of amaurosis fugax compared with the expected survival for the equivalent age and sex in England and Wales, 1975.

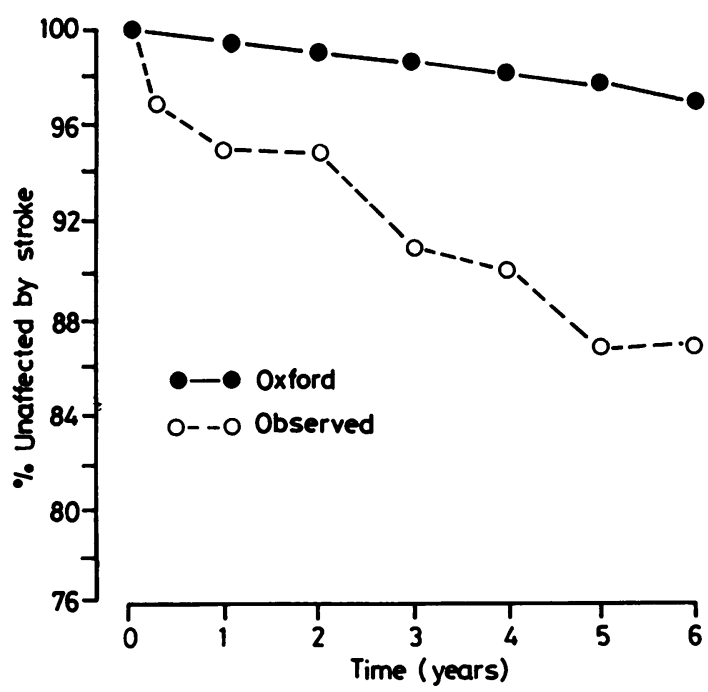

Fig 3 Survival free of stroke for males and females combined after one or more attacks of amaurosis fugax compared with the expected stroke rate for the equivalent age and sex in Oxfordshire 1981-1983.

\section{Discussion}

Patients experiencing uniocular blindness areo alarmed and usually report to their general prac? titioner after one or two attacks. ${ }^{3}$ They are cus- 8 tomarily rapidly referred to hospital and so thiso sample is probably representative of amaurosis fugax in the greater London area.

This study shows that patients who have amaurosis fugax frequently die from ischaemic heart disease. The mortality rate per year is approximately constant over six years. At six years after presentation the number of fatal cardiac events is approximately four times the expected number for England and Wales. An increased risk of ischaemic heart disease is not surprising since the suggested aetiology of amaurosis fugax is embolism from carotid atheroma and there is a close relationship between severity of atheroma in carotid and coronary arteries. ${ }^{?}$

Table 4 Results of angiography

\begin{tabular}{lll}
\hline & $\begin{array}{l}\text { No } \\
(N=64)\end{array}$ & $\begin{array}{l}\text { Stroke during } \\
\text { follow up } \\
(N=10)\end{array}$ \\
\hline $\begin{array}{l}\text { Normal carotid angiogram } \\
\begin{array}{l}\text { Stenosis or atheroma of } \\
\text { proximal ICA }\end{array}\end{array}$ & 35 & 1 \\
$\begin{array}{l}\text { Occluded ICA } \\
\text { Other lesions }\end{array}$ & 15 & 6 \\
$\begin{array}{l}\text { Unsuccessful angiogram/result } \\
\text { unavailable }\end{array}$ & 4 & 2 \\
\hline
\end{tabular}

ICA = Internal carotid artery. 
Mortality from all causes six years after amaurosis fugax was 1.4 times greater than expected. This is in agreement with Whisnant's study of first cerebral transient ischaemic attacks ${ }^{8}$ in which there was a 1.3 fold increased risk of death; again cardiac disease was the most frequent cause of death. Although the latter study was in an older American population it appears the increased risk of death conferred by either amaurosis fugax or cerebral transient ischaemic attack is similar.

The Oxfordshire Community Stroke Project 1981-1983 was used to calculate an expected yearly stroke rate weighted according to the age distribution of our amaurosis fugax sample. This is probably the best available community based study for the incidence of first stroke in the South of England. Their estimated yearly incidence of stroke was $1.95 / 1000$ population similar in magnitude to earlier studies. ${ }^{9}$ The relative risk of stroke in our group six years after presentation was four times greater than expected. This may be an underestimate for two reasons. Firstly a stroke prior to death from another cause may not have been recorded. Secondly the sixteen patients excluded on the grounds of surgical treatment all had narrowing of a carotid artery and are in a high risk group for stroke (see below). ${ }^{10}$

Those patients with an occluded or narrowed proximal internal carotid artery on the symptomatic side showed a significantly increased risk of stroke compared with patients with a normal carotid angiogram $(p<0.01)$. This may in part be due to their higher mean age of 63 years compared with 55 years for the latter group.

There were eleven strokes during the first six years of follow up, that is an average stroke rate of $1.8 \%$ per annum. Although we did not study a group of cerebral transient ischaemic attacks this is less than the generally accepted stroke rate of 5 to $10 \%$ per annum after a cerebral transient ischaemic attack. This may in part be due to a high proportion of young patients in our sample or to the exclusion of sixteen surgically treated patients. Another explanation for the better prognosis in ocular ischaemia is that amaurosis fugax may be an earlier and more sensitive index of atherosclerosis than is a cerebral transient ischaemic attack. This may be related to the size of the embolic fragment necessary to block a retinal artery or to the difference in collateral blood supply between brain and retina. Finally it is possible that a separate mechanism unrelated to atherosclerosis may be operating in a proportion of patients with amaurosis fugax this group having an earlier onset and better prognosis. The fact that no patient presenting under the age of 57 years developed a stroke tends to support this view.

We thank Richard Morris, Department of Community Medicine for statistical advice and Miss D Clutterbuck for typing the manuscript.

\section{References}

' Fisher CM. Transient monocular blindness associated with hemiplegia. Arch Ophthalmol 1952;47:167-203.

${ }^{2}$ Heyman A, Leviton A, Millikan $\mathrm{CH}$, et al. Transient focal cerebral ischaemia: Epidemiological and clinical aspects. Stroke 1974;5:277-84.

${ }^{3}$ Marshall J, Meadows S. The natural history of amaurosis fugax. Brain 1968;91:419-34.

4 Morax PV, Aron-Rosa D, Gautier JC. Symptomes et signes ophthalmologiques des stenoses et occlusions carotidiennes. Bulletin de Société Ophthalmologique Francais 1970; Suppl. 1: 169-81.

${ }_{5}^{5}$ Parkin PJ, Kindall BE, Marshall J, et al. Amaurosis fugax: some aspects of management. J Neurol Neurosurg Psychiatry 1982;45:1-6.

- Sandicock PAG. DM thesis in press. Univ. Oxford 1984.

${ }^{7}$ Mitchell JRA, Schwartz CJ. The relationship between arterial disease in different sites. Arterial Disease. Oxford: Blackwell, 1965:69-72.

${ }^{8}$ Whisnant JP, Matsumoto N, Elveback LR. Transient cerebral ischaemic attacks in a community. Mayo Clin Proc 1973; 48: 194-8.

' Chin PL, Angunawela R, Mitchell D, et al. Stroke register in Carlisle: a preliminary report. In: Rose FC, ed. Clinical Neuroepidemiology. Tunbridge Wells: Pitman Medical, 1980:131-43.

${ }^{10}$ Harrison MJ, Marshall J. Prognostic significance of severity of carotid atheroma in early manifestations of cerebrovascular disease. 1982;5:567-9. 